\title{
Alterations of palm oil (Elaeis guineensis) in the continuous industrial par frying of breaded chicken snacks
}

\author{
Débora Rezende FERREIRA ${ }^{1 *}$, Adelaide Del Pino BELÉIA ${ }^{1}$, Rui Sérgio dos Santos Ferreira da SILVA ${ }^{1}$
}

\begin{abstract}
The physical and chemical alterations in palm oil during continuous industrial par frying of breaded chicken snacks were evaluated using a pseudo first-order kinetic model. The acidity index, refractive index, concentration of polar compounds, viscosity, color, and absorbance $(232$ and $268 \mathrm{~nm}$ ) of 238 samples of the frying oil collected during 26 days of production were analyzed. For all of the analyses, the results of the oil were below the limits recommended for oil disposal, indicating that the processing conditions were safe and that under these experimental conditions the oil remained suitable for frying. The linear regressions were significant for refractive index, content of polar compounds, and lightness $\left(\mathrm{L}^{\star}\right)$. The content of polar compounds was determined using a cooking oil tester, and it had the best fit to the proposed model and can be used as an effective index for monitoring palm oil during the continuous par frying of breaded chicken snacks. The high turnover rate of the oil was important for maintaining the oil in good running conditions.
\end{abstract}

Keywords: polar compounds; color; refractive index.

\section{Introduction}

Frying is a common and popular cooking method widely used in food preparation both in the home and in industrial operations. It consists simply of immersing the food in hot oil, and it is considered the single oldest unit operation used in food preparation (Sánchez-Gimeno et al., 2008). Fried products combine flavor, color, and texture appreciated by the majority of consumers, and the consumption of these products has been increasing due to economic and social factors such as lack of time for food preparation and meals consumed outside the home. Frying results in foods with a uniform bright golden color, which improves their presentation, and these aspects have led food manufacturers to make specific products to be fried or for final preparation in the home or in restaurants, for example frozen par fried foods. Par frying of breaded meat products such as appetizers and snacks aims to partially cook the products by immersion in hot oil, preserving the shape of products, ensuring adherence of the floury meal to the meat, and providing the typical crunchy texture.

However, this cooking technique which seems simple, is an extraordinarily complex process that involves many factors such as type of equipment, temperature and processing time, volume and source of the frying oil, and the type of food (Blumenthal, 1991). As result of the processing, chemical and physical alterations occur both in the frying oil and in the processed food, and since part of the frying oil is transferred to the food, there is an increase in the consumption of fats and oils subjected to high temperatures (Blumenthal, 1991; Saguy \& Dana, 2003). Chemical alterations and accumulation of compounds other than triacylglycerol may be viewed as a possible health hazard, and quality control is important when frying foods.

There are two main types of immersion frying: continuous and discontinuous. The industrial market for the preparation of extruded snacks, chips, pre-fried breaded meat products, and fried potatoes uses continuous frying, while the institutional market (fast-food outlets, restaurants, and bakeries) uses discontinuous frying.

The chemical composition of the oil and the physical and physicochemical properties influence the par frying process (Sánchez-Gimeno et al., 2008). Palm oil has greater oxidative stability compared to other commercially available oils due to its fatty acid composition that is almost equal in concentration of saturated fatty acids (palmitic) and unsaturated fatty acids (oleic) (Gunstone \& Padley, 1997).

Several countries, such as France, Spain, Germany, and the Netherlands, have established criteria and regulations for the disposal of frying oil that consider values above $25 \mathrm{~g} 100 \mathrm{~g}^{-1}$ for

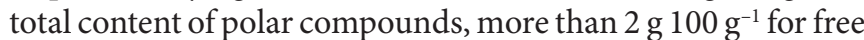
fatty acids, or more than $15 \mathrm{meq} \mathrm{kg}^{-1}$ for the peroxide index as unacceptable for use (Firestone et al., 1991). However, in Brazil, there are no regulations for the monitoring or recommended limit for the disposal of oils and fats used in frying processes.

Chemical alterations in the oil do not result from oxidation reactions only since hydrolysis and thermal polymerization occur. According to the mathematical model proposed by Özilgen \& Özilgen (1990), Equation 1 may explain lipid oxidation in foods based on the reaction mechanisms of free radicals, including initiation, propagation, and termination.

$\frac{d C}{d t}=k C\left(1-\frac{C}{C m a ́ x}\right)$

where $\mathrm{C}$ is the total concentration of oxidation products, $\mathrm{C}_{\max }$ is the maximum value of the $\mathrm{C}$ parameter available at the end 
of lipid oxidation process, $\mathrm{k}$ is the reaction rate constant, and $\mathrm{t}$ is the time.

If $\mathrm{C}<<\mathrm{C}_{\max }$, then the term $1-\mathrm{C} / \mathrm{C}_{\max }$ of Equation 1 approaches zero, an indication of the initial step of the referred mechanism, which can be rewritten as $\mathrm{dC} / \mathrm{dt}=\mathrm{KC}$, which is a first-order equation. In the termination phase, when $\mathrm{C}=\mathrm{C}_{\max }$, the term $1-\mathrm{C} / \mathrm{C}_{\max }$ becomes zero and $\mathrm{dC} / \mathrm{dt}=0$; this indicates the end of the process. These authors have assumed that during the induction phase, the equation can be integrated and rewritten as follows (Equation 2):

$\log C=\log C 0+\frac{k t}{2,303}$

where $\mathrm{C}$ is the total concentration of oxidation products, $\mathrm{C}_{0}$ is the initial concentration $(t=0)$, $t$ is time in hours $(h)$, and $k$ is the reaction rate constant $\left(\mathrm{h}^{-1}\right)$. In the present study, daily average values of each parameter for kinetic model building were used.

The aim of this study was to obtain a mathematical model that fits to the experimental and calculated data that could predict when the palm oil in use should be completely substituted for new oil. in an industrial plant processing frozen chicken meat products or snacks.

\section{Materials and methods}

\subsection{Materials}

Palm oil from Malasia that is used in a continuous par frying process of breaded chicken meat products or snacks was evaluated. The product used was comminuted chicken muscle, which was pre-dusted, battered, breaded, par fried for 24 seconds for better coating adherence, baked, and frozen for final preparation in the home or in restaurants. The oven, designed for roasting (CFS, Cookstar 600, Netherlands), was set at $155^{\circ} \mathrm{C} \pm 5{ }^{\circ} \mathrm{C}$ for $6 \mathrm{~min} 40 \mathrm{~s}$, and the product was then frozen for $40 \mathrm{~min}$ at $-35^{\circ} \mathrm{C}$ (MADEF, TCH 36 inches, Brazil) and stored at $-12{ }^{\circ} \mathrm{C}$.

\subsection{Methods}

\section{Continuous par frying process}

The par frying process was conducted in a continuous industrial fryer, 1,200-liter capacity (Koppens, model BR $600 / 900$ Netherlands). During the par frying process, the following parameters were monitored: temperature of palm oil $\left(190^{\circ} \mathrm{C} \pm 5^{\circ} \mathrm{C}\right)$, frying time (24 seconds), and level of the oil used and replaced. One-day operation resulted in 150 ton of fried snacks.

At the begining of production, the fryer was filled with oil, and oil replacement took place every 15 minutes: approximately $75 \mathrm{~L}$ of oil; a turnover of $4 \mathrm{~h}$. Every 24 hours, all of the oil in the fryer (a minimum of 1,125 liters) was returned to the vat (storage capacity of 6,000 liters) using a pump to clean the fryer thus forming a mixture of used and fresh oil in the vat. A leveling float was used to maintain the proper level of the oil in the vat. As the oil was consumed and the level lowered, it was automatically transferred from the external tank (storage capacity of 30,000 liters) to the internal tank (vat) keeping a volume of 6,000 liters in the internal tank.

The vat was completely emptied every month for cleaning. After cleaning the interior tank, frying restarted with fresh oil, instead of the mixture of used and clean oil, during the entire production process.

\section{Sampling}

The breaded chicken meat processing plant operated from Monday to Saturday, with three daily production shifts. Every day at the end of the third shift, the equipment was cleaned and the frying operation ceased for one hour. A stainless steel ladle was used to collect samples of the used oil maintaining the oil homogeneity using a scraper that was in constant motion inside the fryer.

The first day of sample collection was after the monthly cleaning of the vat, and the process began with new or clean oil, and at every $15 \mathrm{~min} 75 \mathrm{~L}$ of fresh (or new) oil was added to the fryer.

After being used for 23 hours, at the end of the third shift of oil production, the frying oil was transferred to the internal tank for equipment cleaning, and the frying continued using the mixture of fresh and used oil. Therefore, it was possible to evaluate the behavior of the oil during the entire 26-day period of use, excluding Sundays, when all frying operation ceased.

At the beginning of each week, sampling occurred during the three shifts; seven samples were collected during the first hour of production of each shift, producing a total of 21 samples, which were collected in triplicate to produce a grand total of 63 samples. On the other days of production, the samples were collected early in the second shift, which coincided with the halfway point in the work day; on these days, seven samples were collected during 1 hour of production. On the last day of collection, before the tank was cleaned, the samples were collected during the first hour of the three production shifts, resulting in 21 samples. At the end of the entire experiment, 238 samples had been collected.

Spectrophotometric analyses (absorbance at $232 \mathrm{~nm}$ and $268 \mathrm{~nm}$ ) were performed on 7 samples collected from a single day of production per week, totaling 35 samples in the entire experiment.

The oil samples $(200 \mathrm{~mL})$ were placed in amber glass bottles and the headspace was filled with nitrogen and stored at $-5^{\circ} \mathrm{C}$ to avoid subsequent alterations. The samples were thawed only at the time of analysis.

\section{Physicochemical characterization of palm oil}

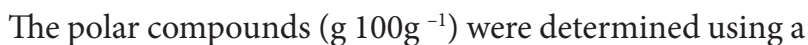
rapid method, a Testo 265 cooking oil analyzer (Testo ${ }^{\circ}$, Brazil). The equipment was immersed in the oil at a temperature of $60{ }^{\circ} \mathrm{C}$, considering the minimum and maximum immersion depth readings in the sensor. The results were expressed in $\mathrm{g}$ 
$100 \mathrm{~g}^{-1}$ of polar compounds and were read directly from the equipment display.

Determination of free fat acid index was performed according to the AOCS official Method Ca 5a-40. The Abbé refractometer (Japan) was used For the determination of the refractive index according to the AOCS official method Cc 7-25 method (Association of Official Analytical Chemistry, 1983). The spectrophotometric analyses (absorbance at $232 \mathrm{~nm}$ and $268 \mathrm{~nm}$ ) were performed with a spectrophotometer (Cintra 20, Australia) using a sample aliquot with absorbance between 0.2 and 0.8 when diluted with 2,2,4 tri mehylpentane (Merck, Brazil), according to the IUPAC Standard Methods (International Union of Pure and Applied Chemistry, 1987).

Viscosity determination was performed using a Brookfield LVDV Prime- $\mathrm{I}^{\circledast}$ viscometer (United States), spindle S18, operating at $20 \mathrm{rpm}$. The oil temperature was measured prior to analysis and maintained with the aid of a thermostatic bath at $50{ }^{\circ} \mathrm{C}$. Seven $\mathrm{mL}$ of oil at $50{ }^{\circ} \mathrm{C}$ were placed in small sample holders, and viscosity and torque were measured in triplicate.

For color measurements, a Konica Minolta Chroma Meter - CR 400 colorimeter (Japan) was used with a $4 \mathrm{~cm}$ diameter sample holder. Color values were expressed according to the CIELAB system with reference to illuminant D65 (natural daylight) and an observer angle of $10^{\circ}$. A thermostatic bath was used to maintain a temperature of $50{ }^{\circ} \mathrm{C}$ at the time of analysis. The colorimeter provided the numerical values for the parameters $\mathrm{L}^{\star}$ (lightness), $\mathrm{a}^{\star}$ (red-green component), and $\mathrm{b}^{\star}$ (yellow-blue component).

\section{Statistical analysis}

The comparisons between the analytical results of the shifts or sampling days, obtained during the experimental period, were calculated for the differences between successive sampling times. ANOVA was used to test the data, and the Tukey test was applied to compare the means (Statsoft, 2007). To study the kinetics of the changes in the acidity index, refractive index, content of polar compounds, viscosity, $\mathrm{L}^{*}, \mathrm{a}^{*}, \mathrm{~b}^{\star}$, and absorbance at $232 \mathrm{~nm}$ and $268 \mathrm{~nm}$, these parameters were modeled by a pseudo firstorder kinetics equation. The data used for this study included the average results from each collection day. On the days when sampling was performed during the three shifts, the average results per shift were considered, which means three results from the same production day.

\section{Results and discussion}

Considering the 24 days of frying, $23 \mathrm{~h}$ a day, at the various sampling times, and considering the free fat acid, refraction, content of polar compounds, viscosity, and lightness, the content of polar compounds was the only one that accumulated continuously (Table 1).

The free fat acid index ranged between 0.21 and $0.64 \mathrm{~g}$ $100 \mathrm{~g}^{-1}$ in free oleic acid equivalent, and the maximum value was reached on the $13^{\text {th }}$ day. Du Plessis \& Meredith (1999) used palm oil for frying potato chips in an industrial plant for $30.5 \mathrm{~h}$ with the production of $2000 \mathrm{~kg} \mathrm{~h}^{-1}$ and replacement of $620 \mathrm{~kg}$ of oil per hour. These authors found a maximum value of $0.41 \mathrm{~g}$ $100 \mathrm{~g}^{-1}$ in free fatty acids (FFA), while Simmone \& Eitenmiller (1998) found an increase of $0.87 \mathrm{~g} 100 \mathrm{~g}$ in FFA compared to the initial value after using the oil for $30 \mathrm{~h}$; but these authors used a domestic fryer with $1.6 \mathrm{~kg}$ of oil. Refractive index increased from 1.4610 initially to 1.4680 on the last day of frying; such increase was accompanied by the accumulation of polar compounds. The refractive index increased with the accumulation of polymer compounds.

The total polar compound content ranged from 6.0

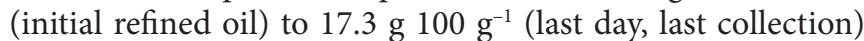

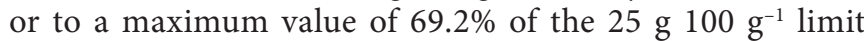
recommended by some countries such as France, Spain, and Belgium (Firestone et al., 1991). Du Plessis \& Meredith (1999),

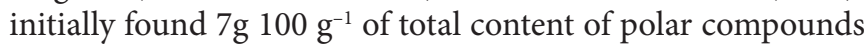
in palm olein used for potato chips production, using an industrial fryer with capacity of $2,000 \mathrm{~kg} \mathrm{~h}^{-1}$ of production and oil uptake of $620 \mathrm{~kg}$ per hour with replacement; and after $30.5 \mathrm{~h}$ of frying operation, the total content of polar compounds was

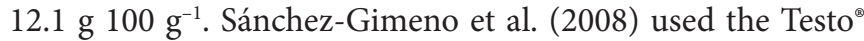
to determine the total content of polar compounds and found an increase from 9 to $20 \mathrm{~g} 100^{-1} \mathrm{~g}$ for olive oil and from 13

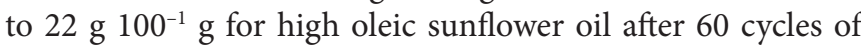
potato frying, and these authors attributed the difference in polar compounds to the higher concentration of linoleic fatty

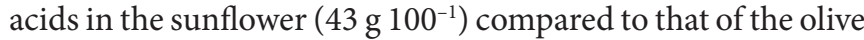

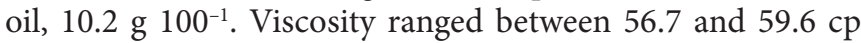
at $20 \mathrm{rpm}$, but the change was not continuous, and higher viscosities were determined on the $19^{\text {th }}$ day of sampling when it reached a plateau. Simmone \& Eitenmiller (1998) found an increase of $34.6 \mathrm{cP}$ for palm olein used for $30 \mathrm{~h}$ to fry frozen chicken nuggets and breaded shrimp in discontinuous frying without oil replacement using a Brookfiel RVTD with a $n^{\circ} 2$ spindle; however, they did not report initial or final values, only this increase. Sánchez-Gimeno et al. (2008) reported an increase from 60 to $110 \mathrm{mPas}$ for olive oil and from 78 to $90 \mathrm{mPas}$ for high oleic sunflower oil using a Bohlin CS-ETO rheometer.

Lightness varied from 42.0 (initial refined oil) to 38.2 (on the $19^{\text {th }}$ day of production) and then to 40.2 on the last day of production. Simmone \& Eitenmiller (1998) obtained a decrease of 6 units in lightness in their frying experiment with palm olein. The color of the oil varied with the frying time: a ${ }^{*}$ varied from -1.28 (green) on the first day of use to -0.3 because the green intensity decreased as the yellow color increased. Yellow $\left(b^{*}\right)$ varied from 12.6 on the first day to 16.1 on the $19^{\text {th }}$ day, decreasing again up to the last day of frying. Du Plessis \& Meredith (1999) found that frying potato chips initially darkened the palm oil rapidly, but after $3 \mathrm{~h}$, the color red had reached the maximum value (from 5.4 to 15.2), while yellow only reached the maximum after $13 \mathrm{~h}$ of use changing from 1.0 to 7.0; it was determined using the Lovibond Tintometer method.

Changes in the absorbance at $232 \mathrm{~nm}$ increased continuously only during the first week of frying and then decreased, from 2.908 initially to 3.558 , on the $6^{\text {th }}$ day and decreased again to 3.014 on the last day of frying (Table 2). Absorbance at $268 \mathrm{~nm}$, which was initially 0.839 , increased to 1.1558 on the 13 day and decreased to 0.925 on the last day of frying (Table 2). Palm 
Table 1. Average values ( 7 samples with 3 replicates each) comparing different shifts and weeks of production of palm oil used in the frying of chicken snacks*.

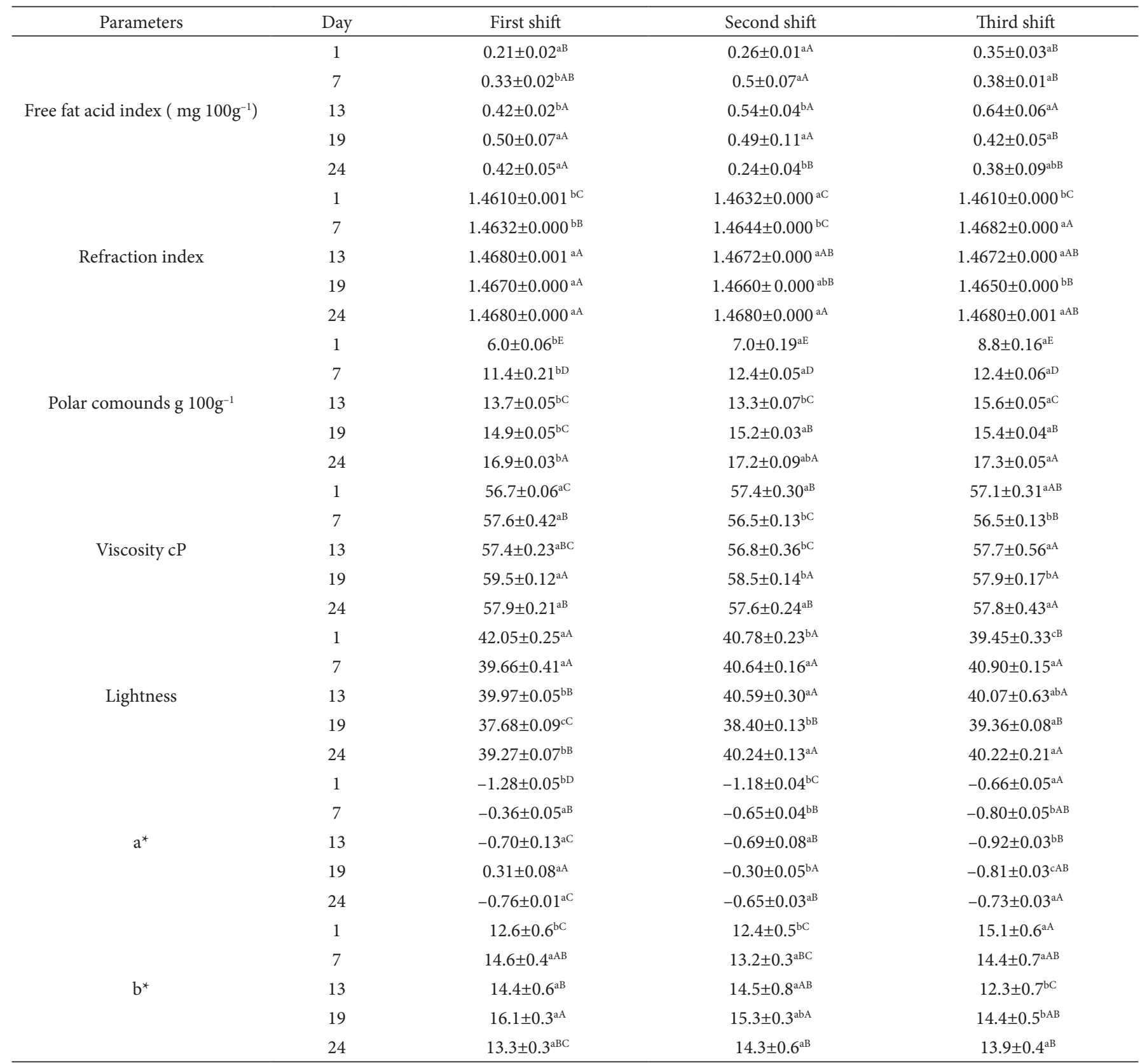

${ }^{*}$ Means \pm standard deviation in the same column followed by the same capital letters do not differ at $\mathrm{p} \leq 0.05$ for each parameter. Mean \pm standard deviation in the same line followed by the same lowercase letters do not differ at $\mathrm{p} \leq 0.05$. L from black $(0)$ to white $(100)$; $\mathrm{a}^{\star}$ from red (+a) to green $(-\mathrm{a})$; $\mathrm{b}^{\star}$ from yellow $(+\mathrm{b})$ to blue $(-\mathrm{b})$.

Table 2. Average absorption ( 7 samples, 3 repetitions) at $232 \mathrm{~nm}$ and $268 \mathrm{~nm}$ of palm oil used in the frying of chicken snacks*.

\begin{tabular}{ccc}
\hline Days of frying & $\mathrm{A}_{232 \mathrm{~nm}}$ & $\mathrm{~A}_{268 \mathrm{~nm}}$ \\
\hline 1 & $2.908 \pm 0.017^{\mathrm{E}}$ & $0.839 \pm 0.015^{\mathrm{D}}$ \\
6 & $3.558 \pm 0.021^{\mathrm{A}}$ & $1.145 \pm 0.017^{\mathrm{A}}$ \\
12 & $3.404 \pm 0.011^{\mathrm{B}}$ & $1.158 \pm 0.011^{\mathrm{A}}$ \\
18 & $3.303 \pm 0.018^{\mathrm{C}}$ & $1.069 \pm 0.022^{\mathrm{B}}$ \\
24 & $3.014 \pm 0.030^{\mathrm{D}}$ & $0.925 \pm 0.012^{\mathrm{C}}$ \\
\hline
\end{tabular}

${ }^{*}$ Means \pm standard deviation in the same column followed by the same capital letters do not differ at $\mathrm{p} \leq 0.05 .{ }^{\star}$ Oil samples: (samples of the first week / first day of the experiment), 6 (samples of the second week), 12 (samples of the third week), 18 (samples of the fourth week), and 24 (samples collected on the last day of experiment). olein does not have a tendency to form conjugated dienes and trienes since it has a low concentration of poly unsaturated fat acids (White, 1991).

\subsection{Kinetic analysis}

The regression model was significant $(\mathrm{p}<0.05)$ for the refractive index and the lightness $\left(\mathrm{L}^{*}\right)$ value. However, the coefficients of determination, proportion of variation in $y,\left(L^{*}\right.$ and refractive index) versus time, were not suitable to calculate point estimates or had a poor predictive capacity (Table 3 ). A negative value of the rate constant of lightness means that 
Table 3. Regression models for the determinations.

\begin{tabular}{cccccc}
\hline Determination & $\mathrm{n}$ & $\mathrm{p}$ & model & $\mathrm{k} \times 10^{-3} \mathrm{~h}^{-1}$ & $\mathrm{r}^{2}$ \\
\hline $\begin{array}{c}\text { Free fatty acid } \\
\text { mg 100g-1 }\end{array}$ & 238 & 0.123 & $\mathrm{y}=1.58 \mathrm{E}-4 \mathrm{x}+0.33$ & 0.364 & 0.071 \\
$\begin{array}{c}\text { Refraction index } \\
\text { Polar compounds }\end{array}$ & 238 & 0.000 & $\mathrm{y}=8 \mathrm{E}-6 \mathrm{x}+1.46$ & 0.018 & $0.495^{*}$ \\
$\mathrm{~g} \mathrm{100 \textrm {g } ^ { - 1 }}$ & 238 & 0.000 & $\mathrm{y}=1.51 \mathrm{E}-2 \mathrm{x}+8.71$ & 34.88 & $0.941^{*}$ \\
$\mathrm{~L}^{*}$ & 238 & 0.024 & $\mathrm{y}=1.96 \mathrm{E}-3 \mathrm{x}+40.16$ & -4.51 & $0.146^{*}$ \\
$\mathrm{a}^{*}$ & 238 & 0.139 & $\mathrm{y}=4.45 \mathrm{E}-4 \mathrm{x}-0.75$ & 1.02 & 0.065 \\
$\mathrm{~b}^{*}$ & 238 & 0.494 & $\mathrm{y}=7.5 \mathrm{E}-4 \mathrm{x}+13.7$ & 1.66 & 0.013 \\
$\mathrm{~A}_{232 \mathrm{~nm}}$ & 35 & 0.671 & $\mathrm{y}=3.56 \mathrm{E}-4 \mathrm{x}+1.27$ & 0.82 & 0.001 \\
$\mathrm{~A}_{268 \mathrm{~nm}}$ & 35 & 0.786 & $\mathrm{y}=1.4 \mathrm{E}-5 \mathrm{x}+1.01$ & -0.32 & 0.002 \\
\hline
\end{tabular}

*Significant model.

there was a decrease in lightness or an increase in the darkness of palm oil during the frying process; however, the variability was 3.8 units.

The best fit of the proposed model was for polar compounds concentration, which resulted in a determination coefficient of 0.941 ; this means that $94.1 \%$ of the variation in the content of polar compounds (y) was explained by the time of use, the independent variable $(\mathrm{x})$. There was good agreement between the experimental and estimated data since they were within the confidence interval of 95\% (Figure 1). The experimental and estimated values of the last day were similar, suggesting an increase in the probability to estimate the time for oil disposal point of the oil based on the concentration of content of polar compounds, which is a fast and convenient method for the industry, with the Testo ${ }^{\circ}$ instrument.

Houhoula et al. (2002) found similar results in studying the kinetics of changes in cottonseed oil during discontinuous frying without oil replacement. They reported a linear increase in the polar compound content during frying with a good coefficient of determination $\left(\mathrm{r}^{2}\right)$, and a reaction rate constant of $1.971 \mathrm{~h}^{-1}$ with a temperature of the frying oil of $195^{\circ} \mathrm{C}$.

The total content of polar compounds increased at a constant rate for a first order model, 1.286 for olive oil and $1.351 \mathrm{~h}^{-1}$ for sunflower oil, which according to these authors, means an almost indefinitely use of the oil. The lower constant of velocity for the palm oil, $0.035 \mathrm{~h}^{-1}$, can be explained by the fact that the potatoes took longer to cook compared to the time taken for the chicken snacks $(24 \mathrm{sec}$ ) and to the use of a 3L capacity fryer for the discontinuous frying.

\subsection{Maintenance and turnover}

The fryer had a turnover rate of $4 \mathrm{~h}(300 \mathrm{~L} / \mathrm{h})$, i.e, at every 4 hours all of the oil had been substituted. There was a daily cleaning of the fryer with scraping of any polymerized material that had adhered to the walls of the fryer. Paul \& Mittal (1997), reviewing data from the literature, affirmed that the turnover rate is probably the most important factor in maintaining oil quality in frying operations. Romero et al. (1999) argued that it would not be possible to maintain almost indefinitely oil quality if replenishment was frequent and recommended decreasing the amount of content of polar compounds to $10 \mathrm{~g} 100 \mathrm{~g}$ for discarding the oil.

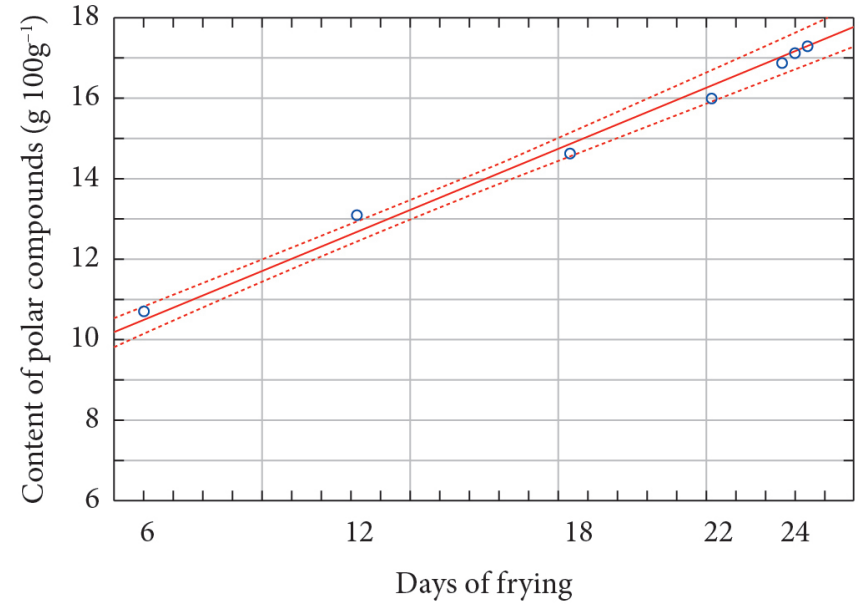

Figure 1. Comparison of predicted data with the experimental data in a confidence interval of $95 \%$ for the parameter of polar compounds.

Wu \& Nawar (1986), described a method for monitoring frying oils that would not be affected by the replenishment for the oil absorbed by the food, but no single index was considered good enough. They used corn oil and fried potatoes, and determined that the ratio of polymer compounds to FOS readings (Foodoil Sensor) was the best response.

At the time of complete replacement of the oil, after the 26 days of experiment, the content of polar compounds had not reached an index that would require the substitution, but the fried snacks probably released animal fat in the oil; therefore, the total substitution of the oil after this period of frying is considered good manufacturing practice.

\section{Conclusions}

Although the turnover (or replacement of the oil used) was high, the polar compounds accumulated in the fryer. The content of polar compounds determined using a fast oil analyzer (model 265, Testo ${ }^{\circ}$ ) was the property that best represented the proposed model, and it may be used as an effective method to monitor the continuous oil-based frying of breaded meat products. 


\section{Acknowledgments}

The authors are grateful for the financial support provided by FUNDETEC / Cascavel.

\section{References}

Association of Official Analytical Chemistry - AOAC. (1983). Official methods of analysis of $A O A C$ (3rd ed.). Champaign.

Blumenthal, M. M. (1991). A new look at the chemistry and physics of deep fat frying. Food Technology, 45(2), 68-71.

Du Plessis, L. M., \& Meredith, A. J. (1999). Palm olein quality parameters changes during industrial production of potato chips. Journal of the American Oil Chemists' Society, 76(6), 731-738. http:// dx.doi.org/10.1007/s11746-999-0168-2

Firestone, D., Stier, R. F., \& Blumenthal, M. (1991). Regulation of frying fats and oils. Food Technology, 45(2), 90-94.

Gunstone, F. D., \& Padley, F. B. (1997). Lipid Technologies and applications. New York: Marcel Dekker, Inc. 834 p. PMid:9397410.

Houhoula, D. P., Oreopoulou, V., \& Tzia, C. (2002). A kinetic study of oil deterioration during frying and a comparison with heating. Journal of the American Oil Chemists' Society, 79(2). http://dx.doi. org/10.1007/s11746-002-0447-0

International Union of Pure and Applied Chemistry - IUPAC. (1987). Standard methods for the analysis of oils, fats and derivatives (7th ed.). Boston: IUPAC. Method 2505.

Özilgen, S., \& Özilgen, M. (1990). Kinetic model of lipid oxidation in foods. Journal of Food Science, 55(2), 498-502. http://dx.doi. org/10.1111/j.1365-2621.1990.tb06795.x
Paul, S., \& Mittal, G. S. (1997). Regulating the use of degraded oil/fat in deep fat/oil frying. Critical Reviews in Food Science and Nutrition, 37(7), 635-662. PMid:9408730. http://dx.doi. org/10.1080/10408399709527793

Romero, A., Cuesta, C., \& Sanchez-Muniz, F. J. (1999). Does frequent replenishment with fresh monoenoic oils permit the frying of potatoes indefinitely? Journal of Agricultural and Food Chemistry, 47, 1168-1173. PMid:10552433. http://dx.doi.org/10.1021/jf980675+

Saguy, I. S., \& Dana, D. (2003). Integrated approach to deep fat frying: engineering, nutrition, health and consumer aspects. Journal of Food Engineering, 56, 143-152. http://dx.doi.org/10.1016/S02608774(02)00243-1

Sánchez-Gimeno, A. C., Negueruela, A. I., Benito, M., Vercet, A., \& Oria, R. (2008). Some physical changes in Bajo Aragón extra virgin olive oil during the frying process. Food Chemistry, 110, 654-658. http://dx.doi.org/10.1016/j.foodchem.2008.02.057

Simmone, A. H., \& Eitenmiller, R. R. (1998). Retention of vitamin E and added retinyl palmitate in selected vegetable oils during deep fat frying and in fried breaded products. Journal of Agricultural and Food Chemistry, 46, 5273-5277. http://dx.doi.org/10.1021/jf9802528

Statsoft (2007). STATISTICA for Windows - Computer program manual. Tulsa: Statsoft Inc.

White, P. J. (1991). Methods for measuring changes in deep fat frying oils. Food Technology, 45(2), 75-80.

Wu, P., \& Nawar, W. W. (1986). A technique for monitoring the quality of used frying oils. Journal of the American Oil Chemists' Society, 63, 1363. http://dx.doi.org/10.1007/BF02679603 